\title{
Hot-salt corrosion of alloys PT-7M, 42XHM, Inconel 690, Incoloy 800
}

\author{
Oleg Bykh, Aleksandr Bakhmetev, Natin Sandler, Petr Tryaev*, Anna Ershova, Anatoly Mikhailov, Ekaterina
} Loginova, Aleksey Sozinov

JSC “Afrikantov OKB Mechanical Engineering”, 603074 Burnakovsky Proyezd 15, Nizhny Novgorod, Russia

\begin{abstract}
The Article contains the results of the study performed for the samples made from alloys PT7M, 42XHM, Inconel 690, Incoloy 800 for resistance against hot salt corrosion in the mixture of crystallized $\mathrm{NaCl}$ and $\mathrm{KBr}$ salts, in ratio $300: 1$ by weight, and in the temperature range from $150{ }^{\circ} \mathrm{C}$ to 300 ${ }^{\circ} \mathrm{C}$, both in contact with the air and in a leak-tight autoclave in the atmosphere of saturated water steam. Regularities of hot salt corrosion behavior in the alloys under the study were detected under testing conditions. The atmosphere of saturated water steam inhibits development of halt salt corrosion of alloy ПТ-7M in the entire temperature range of the testing.
\end{abstract}

\section{Introduction}

This study was carried out to evaluate hot-salt corrosion resistance of the tube samples made of PT-7M, 42XHM, Inconel 690, and Incoloy 800 alloys upon contact with crystalline chlorides and alkali metal bromides in the temperature range from $150{ }^{\circ} \mathrm{C}$ to $300{ }^{\circ} \mathrm{C}$, which is typical for heat-exchange equipment operation. Titanium alloys used in heat-exchange equipment are exposed to hot-salt corrosion in the aforementioned salts provided that the appropriate conditions take place [1].

\section{Mechanism of hot salt corrosion of titanium alloys}

The researchers [2 - 4] tie the hot-salt corrosion with a set of consecutive reactions:

$\mathrm{TiO}_{2}$ (solid) $+2 \mathrm{NaCl}$ (solid) $+\mathrm{H}_{2} \mathrm{O}$ (vapor) $\rightarrow$

$\mathrm{Na}_{2} \mathrm{TiO}_{3}$ (solid) $+2 \mathrm{HCl}$ (gas)

Titanium and titanium alloy oxide film reacts with crystalline salts and water forming sodium titanate $\left(\mathrm{Na}_{2} \mathrm{TiO}_{3}\right)$ and hydrogen chloride $(\mathrm{HCl})$ which further reacts with titanium in (2) as follows:

$$
\begin{aligned}
& \mathrm{Ti}(\text { solid })+4 \mathrm{HCl} \text { (gas) } \rightarrow \\
& \mathrm{TiCl}_{4}(\text { gas })+4 \mathrm{H} \text { (gas) }
\end{aligned}
$$

During its release hydrogen is absorbed by the metal which consequently leads to its hydrogenation. Titanium tetrachloride will be hydrolyzed under the influence of water vapors forming hydrogen chloride and, finally, through a set of intermediate hydrolysis products, titanium oxide $\left(\mathrm{TiO}_{2}\right)$ :

$$
\begin{gathered}
\mathrm{TiCl}_{4} \text { (gas) }+\mathrm{H}_{2} \mathrm{O} \text { (vapor) } \rightarrow \\
\mathrm{TiO}_{2} \text { ( } \text { (solid) }+4 \mathrm{HCl} \text { (gas) }
\end{gathered}
$$

Hydrogen chloride can further react with titanium in (2) forming titanium tetrachloride $\left(\mathrm{TiCl}_{4}\right)$, and so on. The suggested mechanism conditions the intensification of hot-salt corrosion.

\section{Materials and procedure of the studies}

The following samples were tested: a $13 \times 1.5 \mathrm{~mm}$ PT-7M alloy tube fragment of $40 \mathrm{~mm}$ length; a $13 \times 1.5 \mathrm{~mm} 42 \mathrm{XHM}$ alloy tube fragment of $20 \mathrm{~mm}$ length; a $25.5 \times 3.5 \mathrm{~mm}$ Inconel 690 alloy tube fragment of $20 \mathrm{~mm}$ length; a $12.5 \times 1.5 \mathrm{~mm}$ Incoloy 800 alloy tube fragment of $20 \mathrm{~mm}$ length. Chemical composition of the samples is available in Tables 1 and 2.

Table 1. Chemical composition of PT-7M and 42XHM samples ( $\%$ mass).

\begin{tabular}{|c|c|c|c|c|c|c|c|c|c|c|c|c|}
\hline Material & $\mathrm{Ni}$ & $\mathrm{Cr}$ & $\mathrm{Fe}$ & $\mathrm{Ti}$ & $\mathrm{Al}$ & $\mathrm{Zr}$ & $\mathrm{Si}$ & $\mathrm{O}$ & $\mathrm{H}$ & $\mathrm{N}$ & $\mathrm{Mn}$ & $\sum_{\text {red }}$ \\
\hline PT-7M & - & - & 0.25 & basis & 1.9 & 2.3 & 0.12 & 0.07 & 0.006 & 0.03 & - & 0.30 \\
\hline 42XHM & basis & 42.1 & 0.6 & 0.25 & 0.4 & - & 0.25 & - & - & - & 0.2 & - \\
\hline
\end{tabular}


Table 2. Chemical composition of Inconel 690 and Incoloy 800 samples (\% mass).

\begin{tabular}{|c|c|c|c|c|c|c|c|c|c|c|c|}
\hline Material & $\mathrm{C}$ & $\mathrm{Ni}$ & $\mathrm{Cr}$ & $\mathrm{Fe}$ & $\mathrm{Mn}$ & $\mathrm{Cu}$ & $\mathrm{Al}$ & $\mathrm{Ti}$ & $\begin{array}{c}\mathrm{Si} \text {, not } \\
\text { more than }\end{array}$ & $\begin{array}{c}\mathrm{S}, \text { not } \\
\text { more than }\end{array}$ & $\begin{array}{c}\mathrm{P}, \text { not } \\
\text { more than }\end{array}$ \\
\hline Inconel 690 & 0.019 & basis & 30.1 & 9.2 & 0.35 & 0.2 & - & 0.5 & 0.35 & 0.003 & 0.0012 \\
\hline Incoloy 800 & 0.09 & 32 & 21.3 & other & 1.45 & 0.73 & 0.47 & 0.24 & 0.81 & 0.007 & - \\
\hline
\end{tabular}

Relative corrosion tests of the samples were conducted in a corrosion test facility (Fig. 1) in a mixture of $\mathrm{NaCl}$ and $\mathrm{KBr}$ crystalline salts taken in a ratio of $300: 1$ by mass, which corresponds to the ratio in sea water; the size of salt crystals did not exceed $0.3 \mathrm{~mm}$. Test duration was $500 \mathrm{~h}$. The test temperatures (150, $180,200,240,290^{\circ} \mathrm{C}$ ) fully cover the temperature range of heat-exchange equipment operation. To exclude any interference, the samples of different materials were tested separately in different digesters; the tests for each temperature were conducted on three samples. During the tests the following conditions were simulated:

- air atmosphere contact behavior;

- water vapor contact behavior.

Before testing, the samples were degreased, washed in distilled water, and dried in the oven at $100^{\circ} \mathrm{C}$. After that they were put in a mixture of salts poured into a ceramic cup which was placed into the digester. When testing under air atmosphere contact the digester cover was not sealed; no water was poured into the digester.

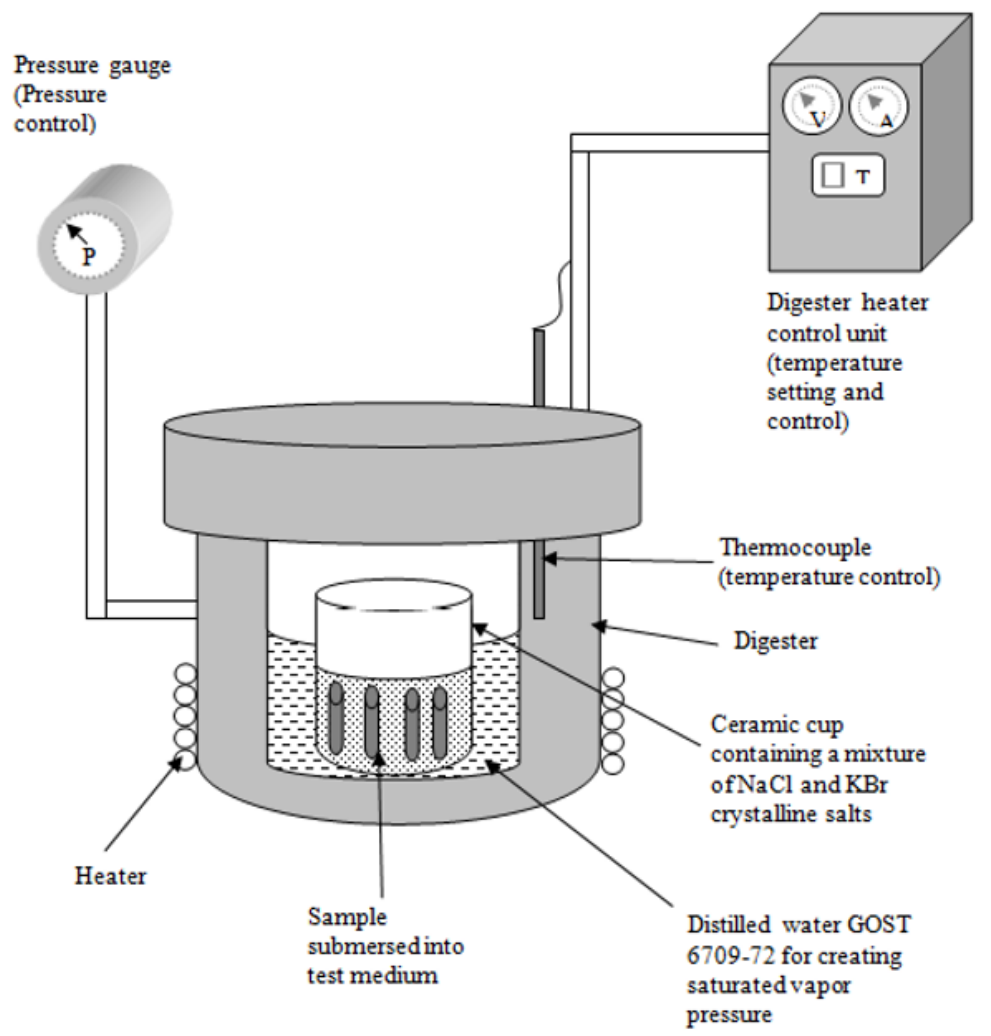

Fig. 1. Corrosion test facility digester.

\section{Results of comparative corrosion testing of samples}

Below are the pictures of PT-7M, 42XHM, Inconel 690, and Incoloy 800 alloy samples after the tests in a mixture of crystalline salts under atmospheric and water vapor pressure in the temperature range of $150-290{ }^{\circ} \mathrm{C}$ (Figs. 2 -9). The pictures of the sample surfaces were taken at $20^{\mathrm{x}}$ zoom. 

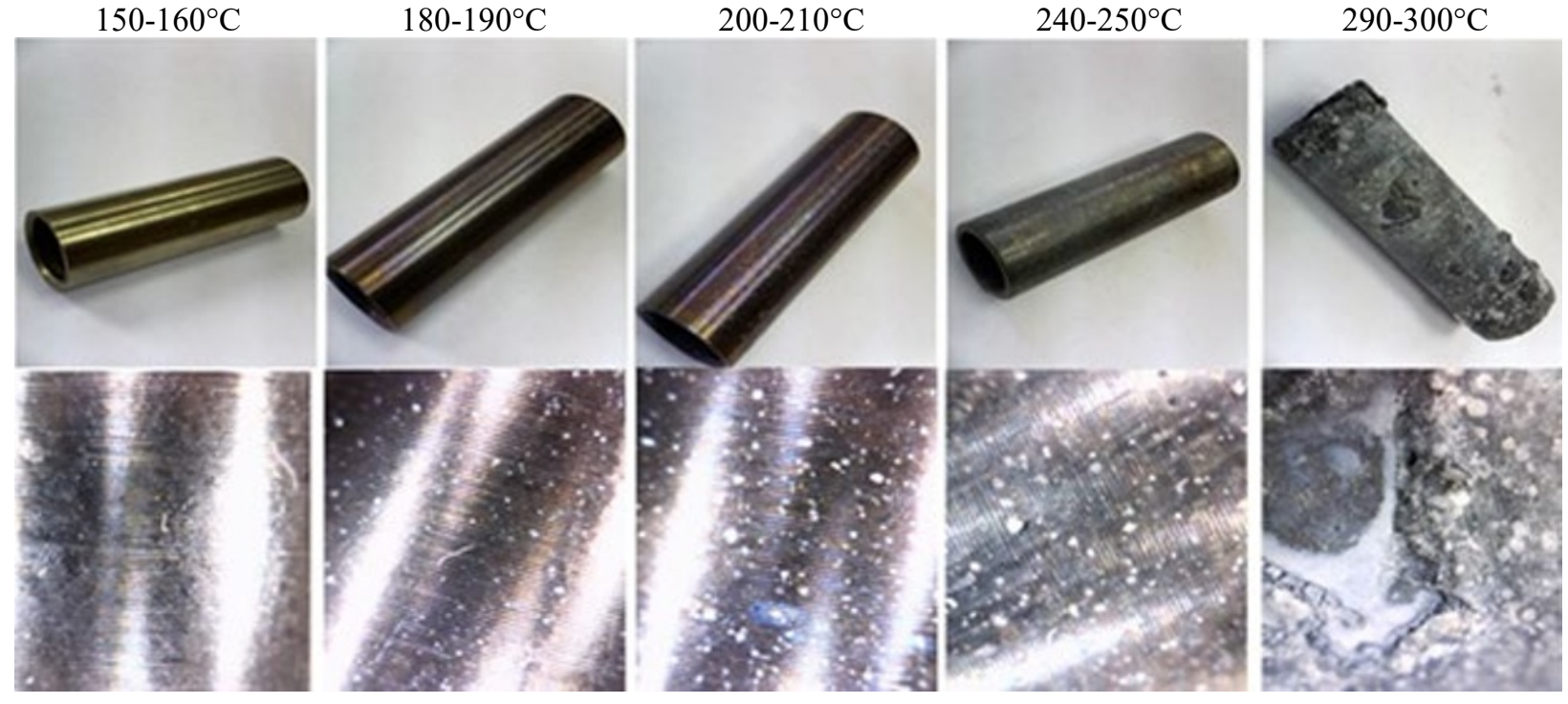

Fig. 2. PT-7M alloy samples after the tests in a mixture of crystalline salts under contact with air atmosphere.
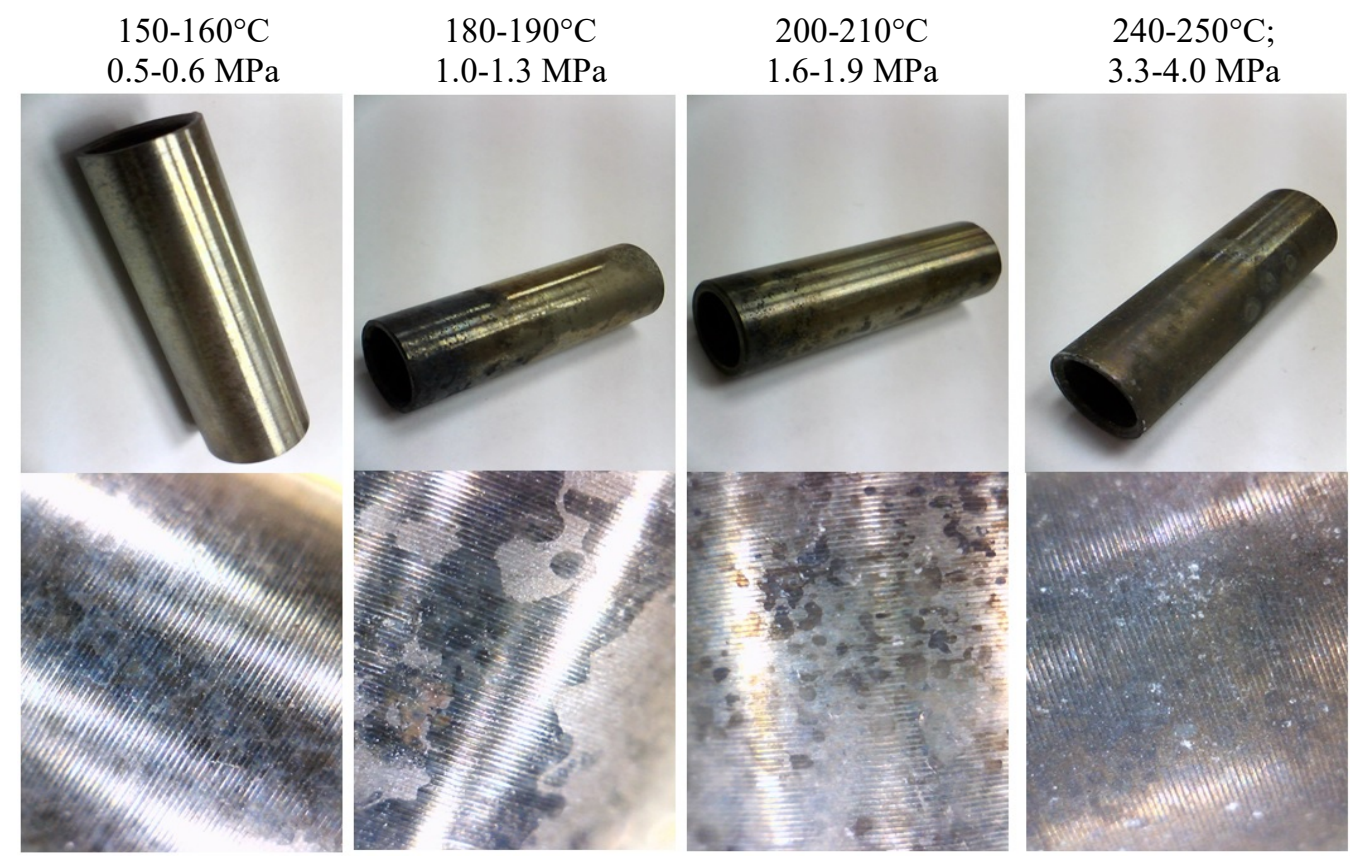

$290-300^{\circ} \mathrm{C}$ 7.4-9.0 $\mathrm{MPa}$

Fig. 3. PT-7M alloy samples after the tests in a mixture of crystalline salts under saturated water vapor pressure. 

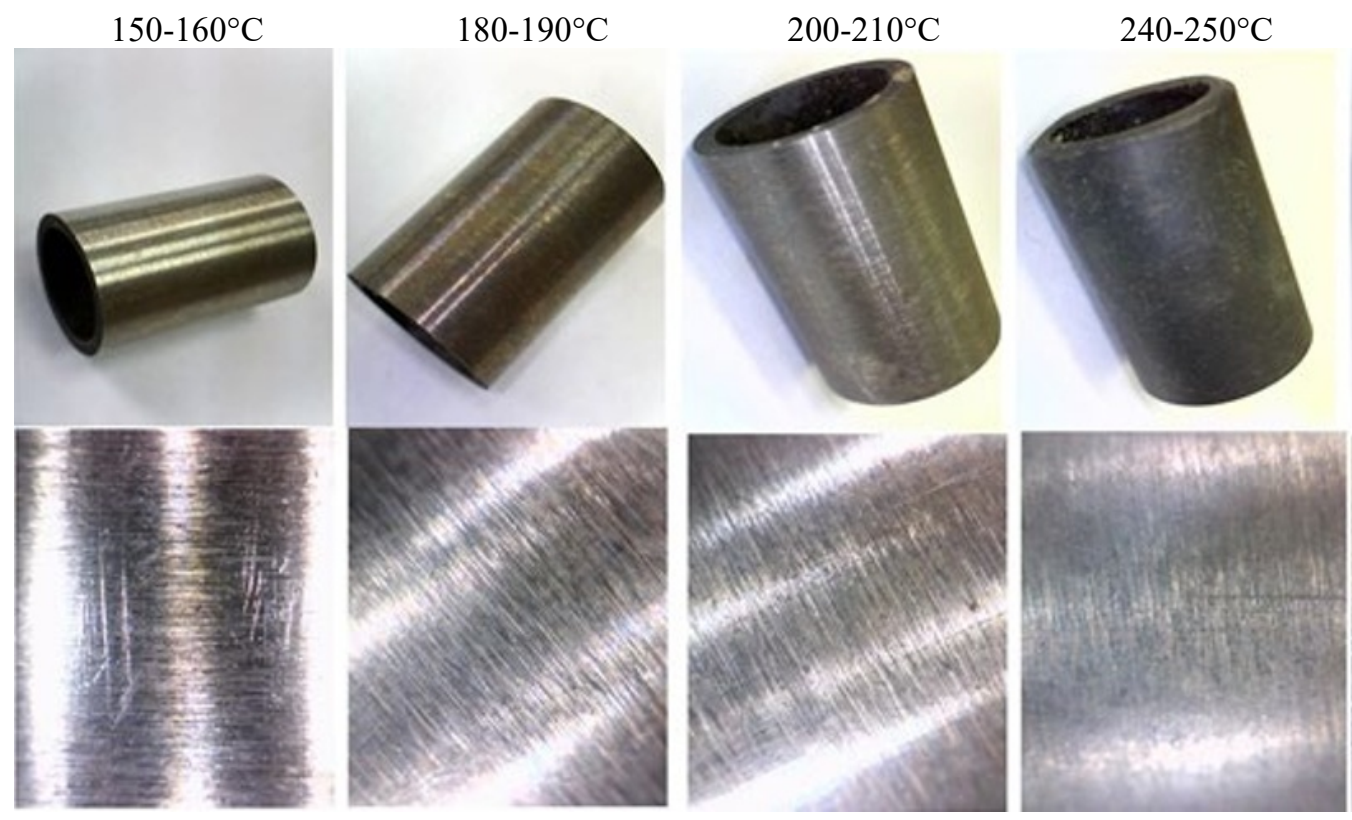

$290-300^{\circ} \mathrm{C}$

Fig. 4. 42XHM alloy samples after the tests in a mixture of crystalline salts under contact with air atmosphere.
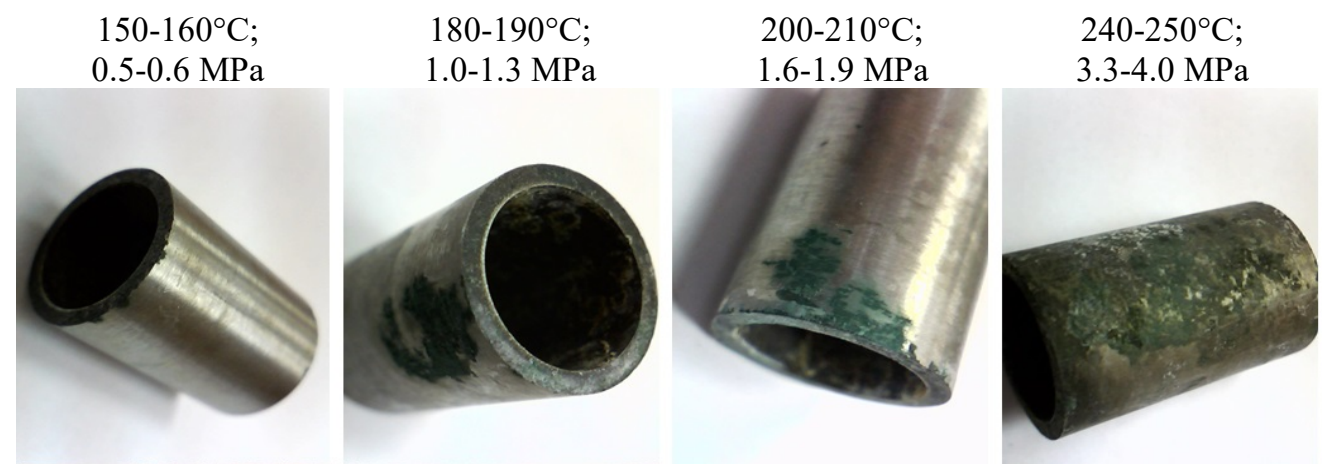

$290-300^{\circ} \mathrm{C}$
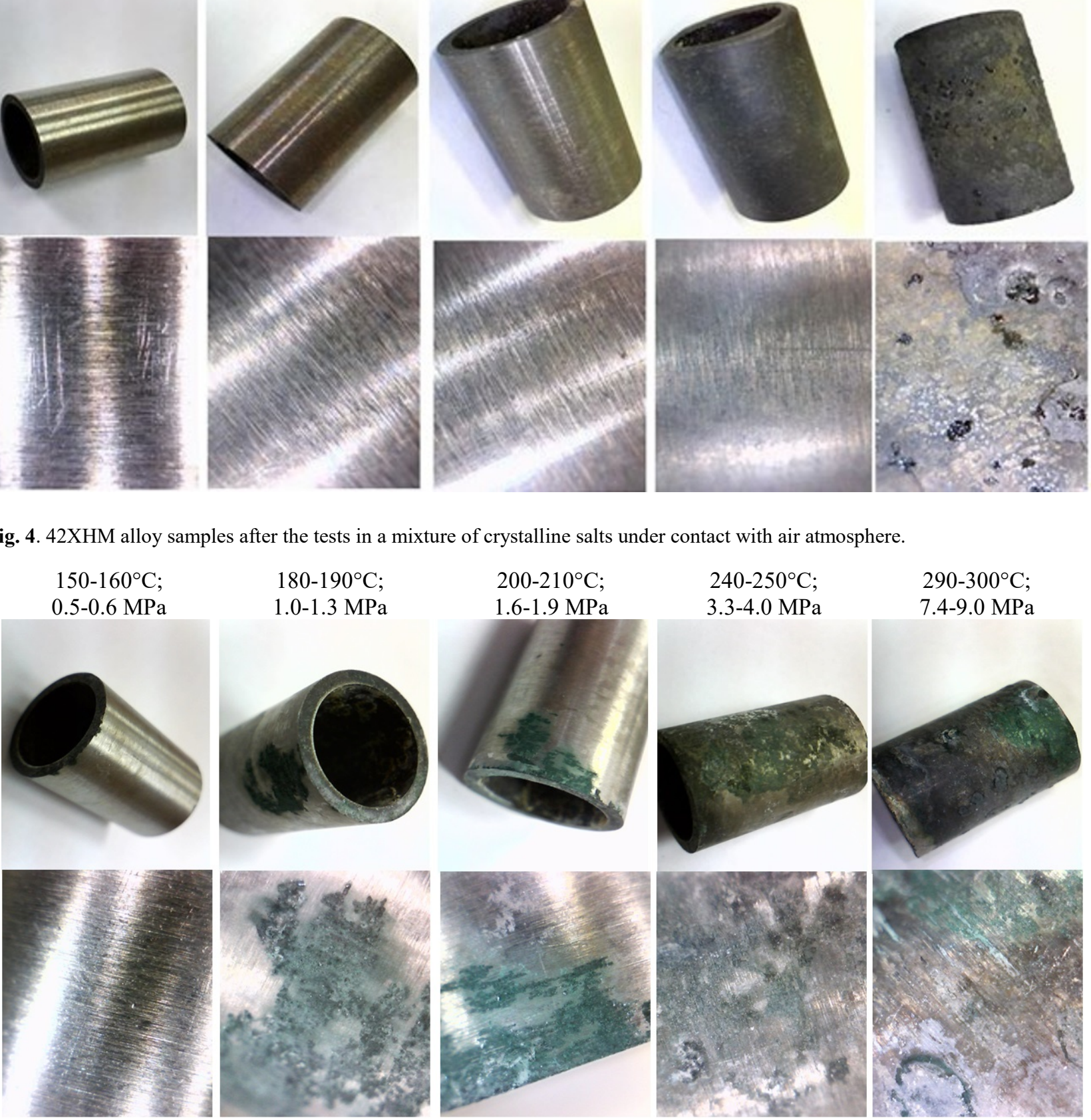

Fig. 5. 42XHM alloy samples after the tests in a mixture of crystalline salts under saturated water vapor pressure. 

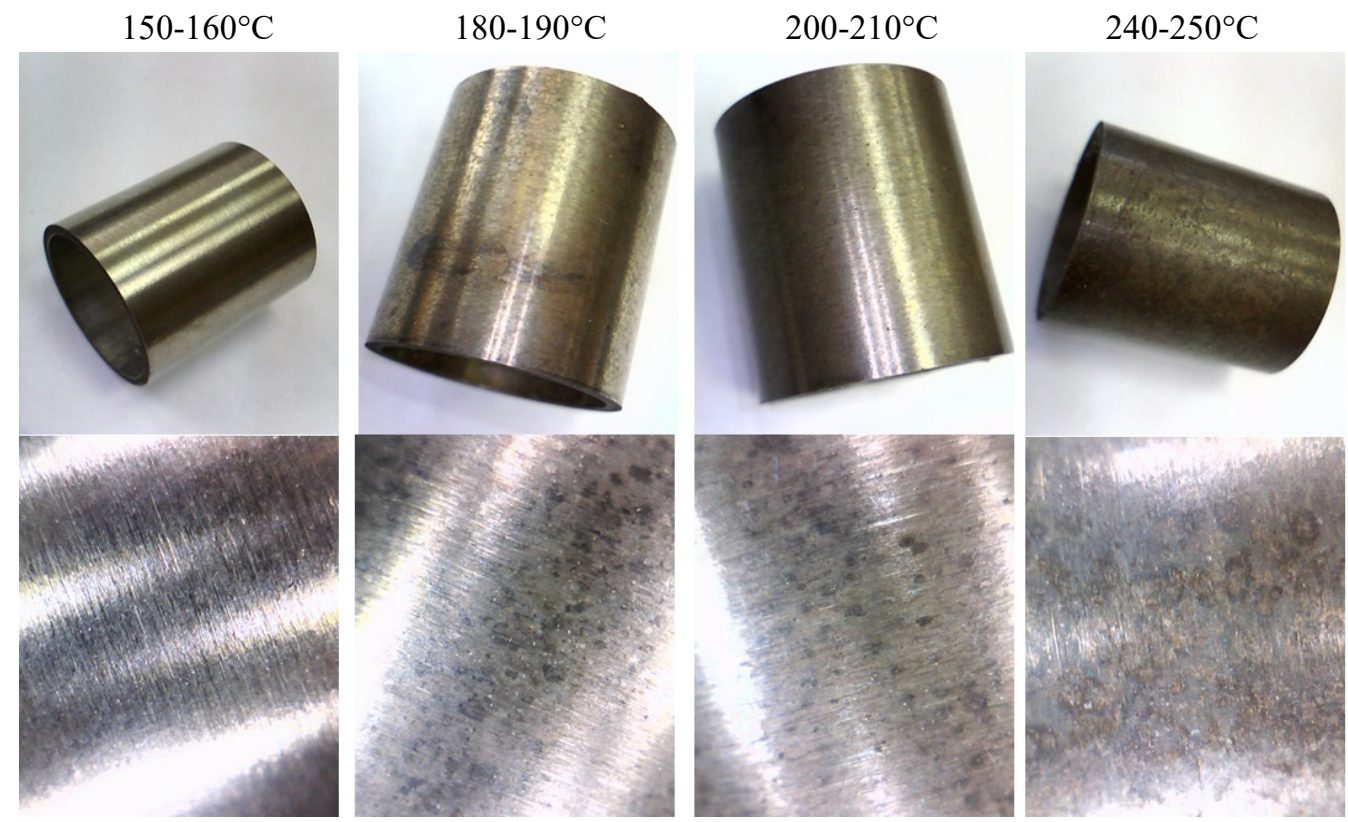

$290-300^{\circ} \mathrm{C}$

Fig. 6. Inconel 690 alloy samples after the tests in a mixture of crystalline salts under contact with air atmosphere.

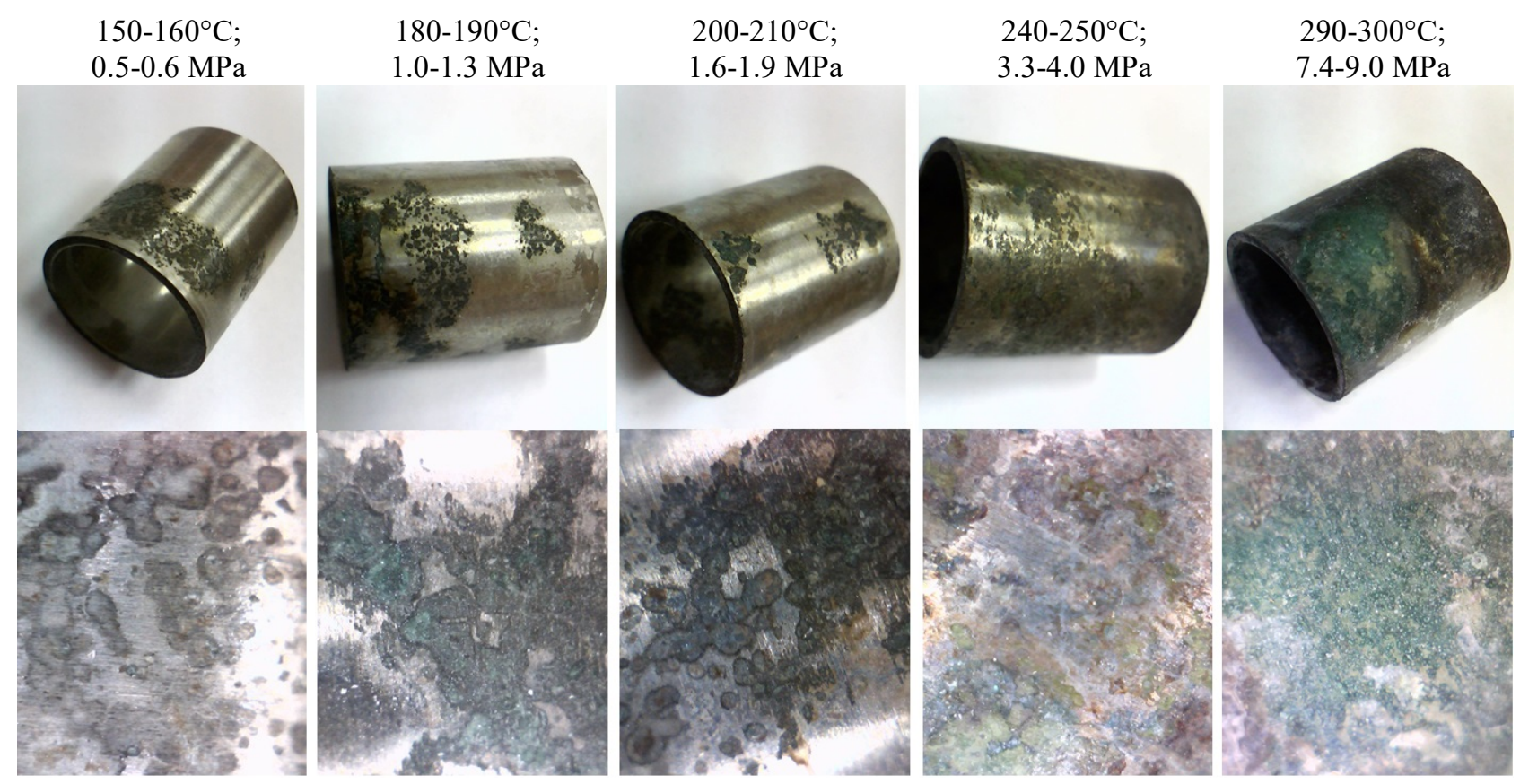

Fig. 7. Inconel 690 alloy samples after the tests in a mixture of crystalline salts under saturated water vapor pressure. 

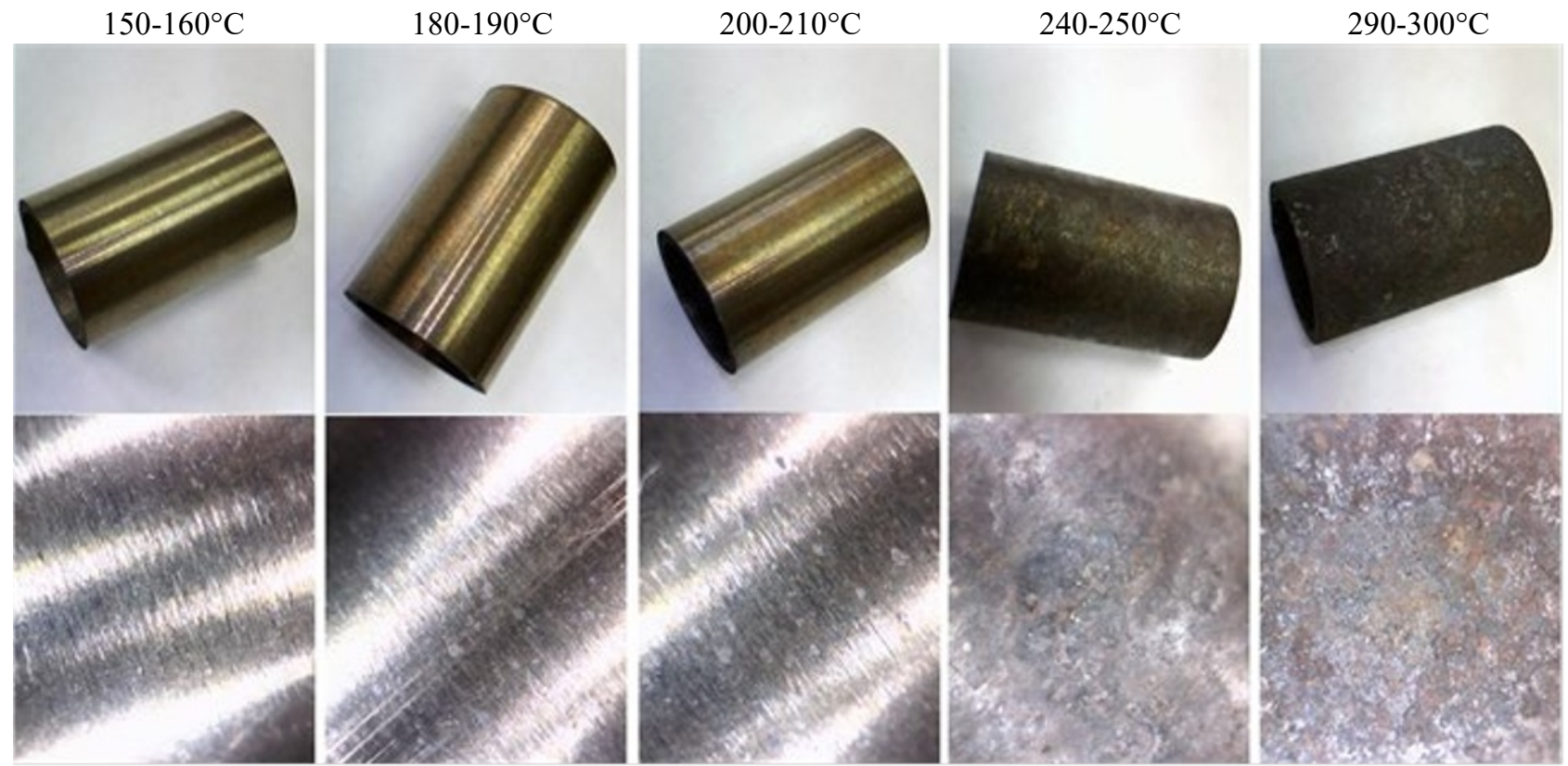

Fig. 8. Incoloy 800 alloy samples after the tests in a mixture of crystalline salts under contact with air atmosphere.
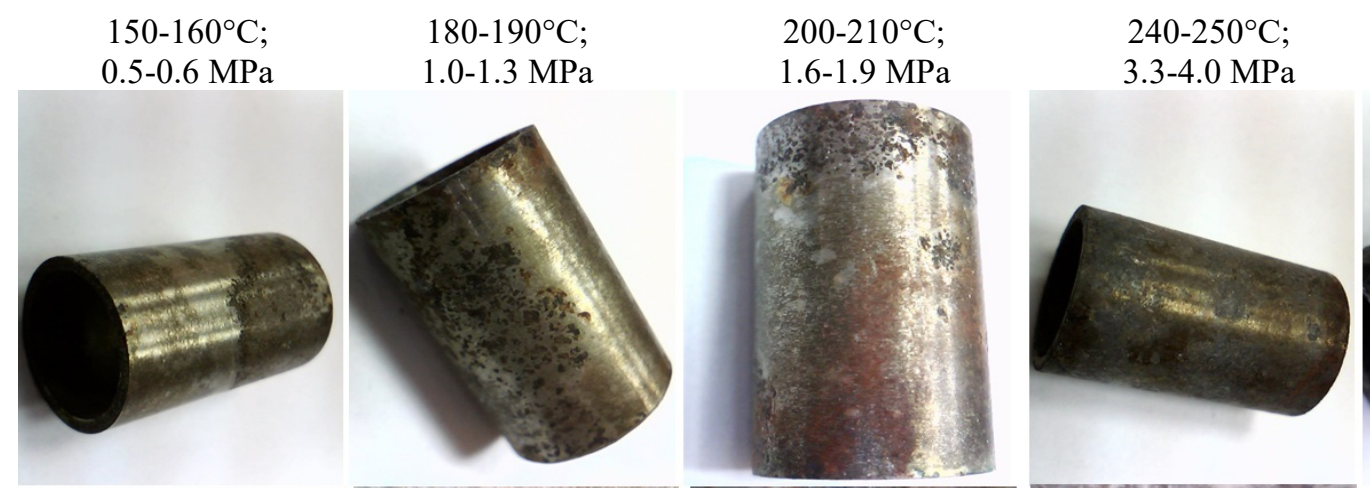

$290-300^{\circ} \mathrm{C}$
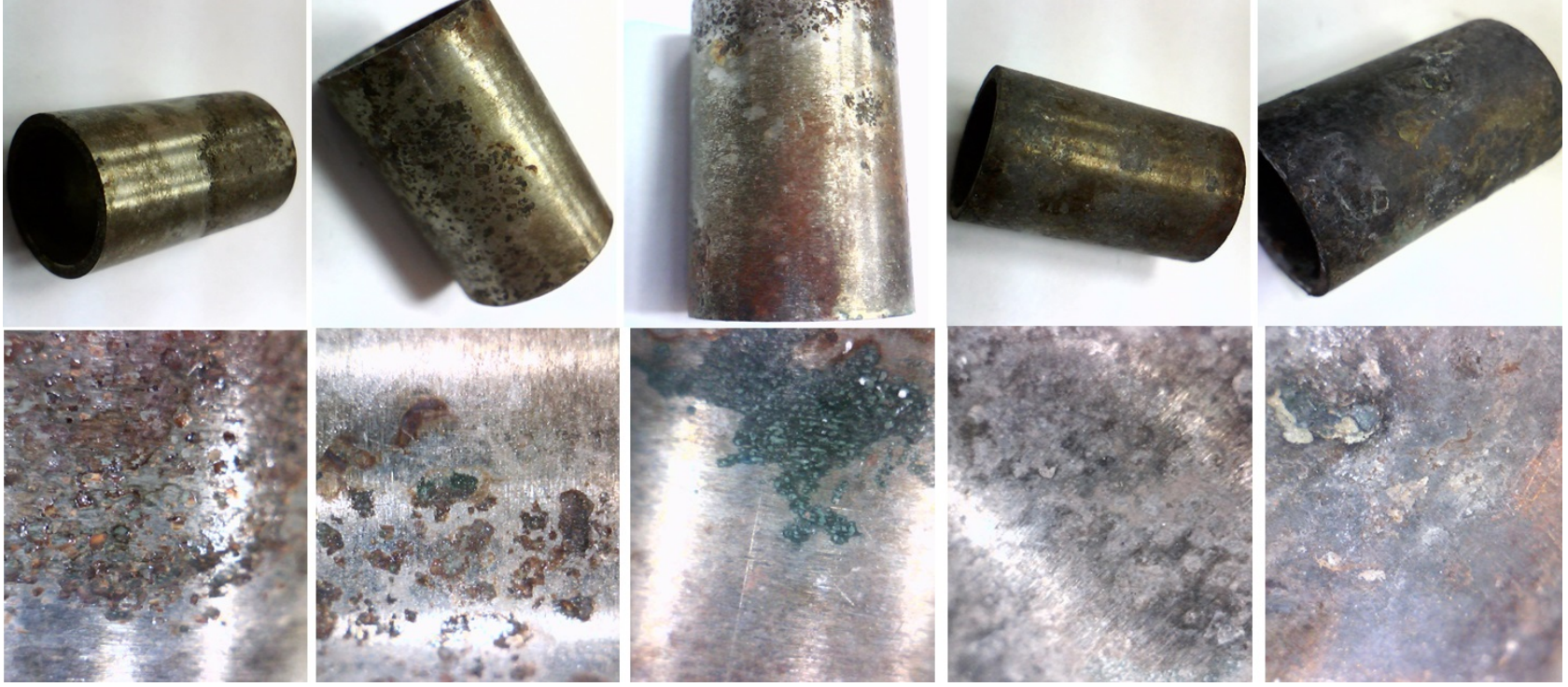

Fig. 9. Incoloy 800 alloy samples after the tests in a mixture of crystalline salts under saturated water vapor pressure.

The rate of the hot-salt corrosion in PT-7M alloy under contact with air atmosphere increases with the temperature rise. The traces of hot-salt corrosion are found at $180-190{ }^{\circ} \mathrm{C}$; with the temperature rise the depth of localized damages, i.e. pits, grows. The surfaces of PT-7M alloy samples, tested at $290-300{ }^{\circ} \mathrm{C}$, show the deepest localized corrosion damages. According to the results of metallographic research we can state that the average pit depth ranges from $0.2 \mathrm{~mm}$ to $0.3 \mathrm{~mm}$, the maximum depth is $0.75 \mathrm{~mm}$. It should be noted that the hot-salt corrosion is of intergranular nature (Fig. 10). Hydrogen content in the metal of the samples, tested at $290-300{ }^{\circ} \mathrm{C}$, was measured in the corrosion damages area, after an appropriate preparation of the sample surface, with the help of a spectral method, and ranged from $0.010 \%$ mass. to $0.014 \%$ mass., which exceeds the initial hydrogen content of $0.006 \%$ mass. in the sample. 


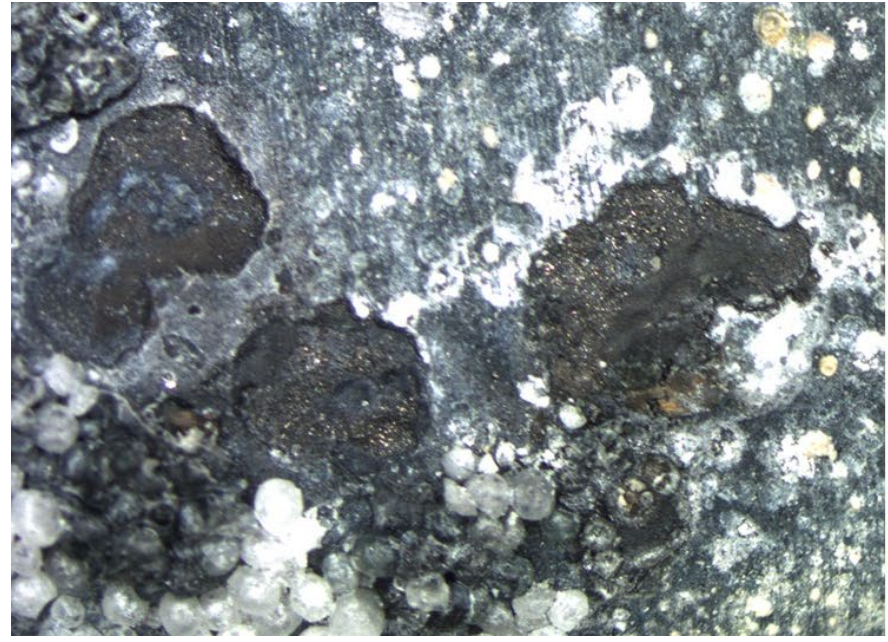

a

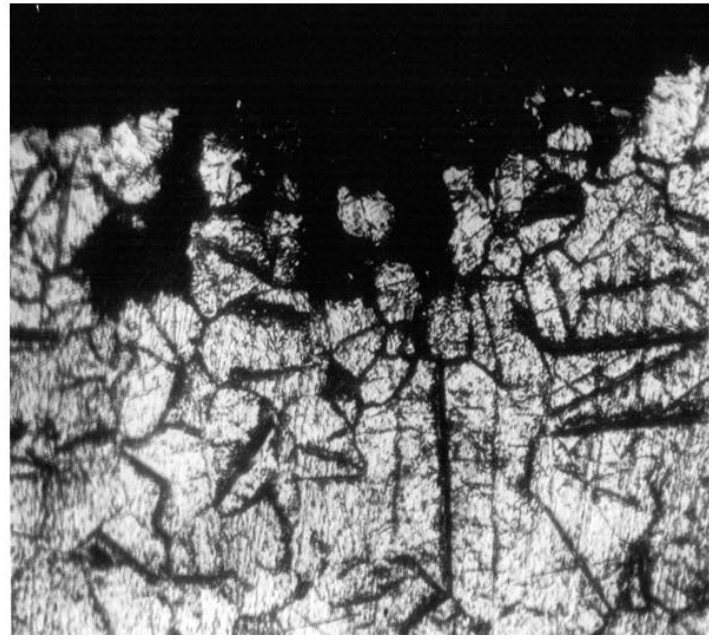

b

Fig. 10. a) localized corrosion damages on the surface of PT-7M alloy samples after the tests under air atmosphere contact at $290-$ $\left.300^{\circ} \mathrm{C}\left(6,5^{\mathrm{x}}\right) . \mathrm{b}\right)$ surface layers condition in the localized damages area at $50^{\mathrm{x}} \mathrm{zoom}$ (intergranular fracture).

As shown in Fig. 3, when research under saturated water vapor atmosphere, the surface of PT-7M alloy samples lost its metallic luster with the temperature and pressure rise. In these conditions no traces of hot-salt corrosion were observed, the sample surfaces passive state was preserved at all test temperatures. Localized surface corrosion to a depth not exceeding the machining marks is observed.

Surfaces of 42XHM alloy samples (Fig. 4), tested in crystalline salts under air atmosphere contact at a temperature from $150{ }^{\circ} \mathrm{C}$ to $250{ }^{\circ} \mathrm{C}$, lost their metallic luster. Surfaces of 42XHM alloy samples, tested at 290 $300^{\circ} \mathrm{C}$, showed localized corrosion damages in the form of pits with corrosion product scurf of green color, i.e. mixtures of oxides, chromium chlorides and nickel

(Fig. 11). When tested in the saturated water vapor medium, surfaces of 42XHM alloy samples (Fig. 5) showed pitting corrosion damages. According to the results of metallographic examination the depth of damages after the tests both in the air and water vapor atmospheres did not exceed $0.15 \mathrm{~mm}$. No intergranular fracture was observed.

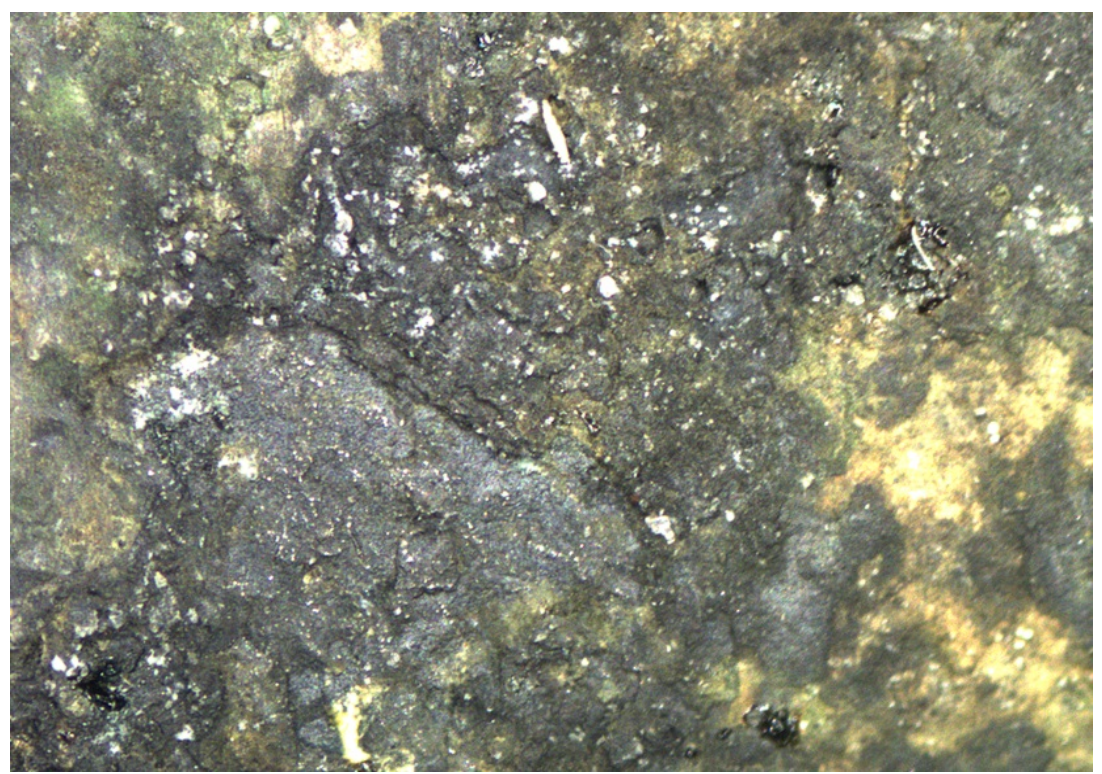

Fig. 11. Localized corrosion damages on $42 \mathrm{XHM}$ alloy sample after the tests under air atmosphere contact at $290-300{ }^{\circ} \mathrm{C}\left(12.5^{\mathrm{x}}\right)$.

After the research under air atmosphere contact at a temperature from $150^{\circ} \mathrm{C}$ to $250^{\circ} \mathrm{C}$, surfaces of Inconel 690 alloy samples (Fig. 6) lost their metallic luster. Surfaces of Inconel 690 alloy samples, tested at $240-$ $250{ }^{\circ} \mathrm{C}, 290-300{ }^{\circ} \mathrm{C}$, are fully covered in general corrosion product deposits. The sample surfaces showed no localized corrosion damages. After the test in the saturated water vapor medium (Fig. 7), the sample surfaces showed localized corrosion damages in the form of elongated pits, the depth of which did not exceed 0.15 $\mathrm{mm}$. 
After the research under air atmosphere contact, surfaces of Incoloy 800 alloy samples (Fig. 8) lost their metallic luster. After the tests at $240-250{ }^{\circ} \mathrm{C}, 290-300$ ${ }^{\circ} \mathrm{C}$ the sample surfaces showed a dense layer of general corrosion products. After the research in the saturated water vapor medium (Fig. 9) at $150-160{ }^{\circ} \mathrm{C}, 180-190$ ${ }^{\circ} \mathrm{C}, 200-210{ }^{\circ} \mathrm{C}$, the surfaces of all Incoloy 800 alloy samples showed corrosion spots the areas of which grow with the temperature rise. The sample surfaces, researched at $240-250{ }^{\circ} \mathrm{C}, 290-300{ }^{\circ} \mathrm{C}$, are covered in a layer of corrosion products. According to the results of metallographic examination, after the research in the air atmosphere and water vapor media, the sample surfaces showed no traces of localized corrosion (pittings, pits, cracks).

The hot-salt corrosion of PT-7M alloy samples under contact with air atmosphere was observed at test temperatures of $180-190{ }^{\circ} \mathrm{C}$ and higher. It appears that the most dangerous behavior for the heat-exchange equipment made of PT-7M alloy is the contact with crystalline chlorides and alkali metal bromides in the air atmosphere at $290-300{ }^{\circ} \mathrm{C}$. Saturated water vapor provides for a stable surface passivation and impedes hot-salt corrosion in the whole analyzed range of temperatures. Basically, this can be explained by an assumption that at high water vapor pressure the formation of titanium tetrachloride is suppressed, as well as are reactions 2 and 3, but it needs to be experimentally validated.

We should note that it is possible to increase the hotsalt corrosion resistance of titanium alloys by decreasing the impurity concentration at grain boundary. Thus, the hot-salt corrosion resistance increase was observed in submicrocrystalline modifications of titanium alloys with grain sizes ranging from $0.2 \mu \mathrm{m}$ to $1 \mu \mathrm{m}$ obtained by equal channel angular extrusion $[5,6]$.

We can state that 42XHM, Inconel 690, and Incoloy 800 alloy samples demonstrated a higher corrosion resistance during the tests as compared to PT-7M alloy samples.

\section{Conclusion}

1. According to the test results, the temperature threshold for the hot-salt corrosion onset in PT-7M titanium alloy under contact with air atmosphere is $180^{\circ} \mathrm{C}$.

2. As for the hot-salt corrosion development the most dangerous behavior for PT-7M alloy is the contact with crystalline salts like chlorides and alkali metal bromides in the air atmosphere at $300{ }^{\circ} \mathrm{C}$ (from the analyzed range of temperatures).

3. Contact with saturated water vapor impedes PT-7M hot-salt corrosion in the whole range of test temperatures.

4. 42XHM, Inconel 690, and Incoloy 800 alloy samples demonstrated a higher corrosion resistance during the tests as compared to PT-7M alloy samples.

\section{References}

1. I.V. Gorynin, B.B. Chechulin, Titanium in mechanical engineering (Moscow, Mechanical engineering, 1990)

2. M. Cash, John R. Nicholls, Hot salt stress corrosion cracking and corrosion fatigue of titanium alloys, High Materials Science Forum, Vols.251-254, pp. 649-656, (1997)

3. D.Sinigaglia, G.Taccani and B.Vicentini, Hot-SaltCorrosion Cracking of Titanium Alloys, Corrosion Scienc, Vol. 18, pp 781-796, (1998)

4. R.S. Ondrejcin, M.R. Louthan, Role of hydrogen Chloride in hot-salt stress corrosion cracking of titanium-aluminum alloys, Report DP (NASA)-1130, USAEC, E.I. du Pont de Nemours and Co, Savannah River Laboratory (1967)

5. V.N. Chuvildeev, P.V. Tryaev et al., Examination of physical-and-mechanical and corrosion properties of Ti-Al-V submicrocrystalline alloy, Bulletin of Lobachevsky State University of Nizhny Novgorod, № 5(1), pp. 38-50, (2013)

6. V.N. Chuvildeev, P.V. Tryaev et al., Effect of simultaneous strength and corrosion resistance increase in microcrystalline titanium alloys, Proc. of RAS Technical Physics, Vol. 442, № 3, pp. 1-4 (2012) 